\title{
Acute Myocardial Infarction in a Young Man with Hyperhomocysteinemia and Pulmonary Tuberculosis
}

\author{
Man-Yi Ren ${ }^{1,2}$, Chun-Sheng Zhang ${ }^{2}$, Xiao-Juan Zhang ${ }^{2}$ and Jing-Quan Zhong ${ }^{1}$
}

\begin{abstract}
Acute myocardial infarction, hyperhomocysteinemia and pulmonary tuberculosis (PTB) are rare in individuals under the age of 30 years. We herein report the case of a 27-year-old man who presented with intermittent chest pain, elevated homosysteine level, and PTB. The patient was treated successfully with a combination of medications and percutaneous coronary intervention. This uncommon case highlights that homocysteine, folate and B vitamins levels should be regularly evaluated, and that chest X-rays or thoracic computed tomography should be ordered routinely to exclude PTB in patients under the age of 30 years who present acute myocardial infarction and lack the traditional risk factors.
\end{abstract}

Key words: acute myocardial infarction, hyperhomocysteinemia, pulmonary tuberculosis, young

(Intern Med 55: 153-159, 2016)

(DOI: 10.2169/internalmedicine.55.4565)

\section{Introduction}

Acute myocardial infarction (AMI) in individuals under the age of 30 years is a rare event, which is usually not related to coronary atherosclerosis, but mostly occurs as a consequence of drug abuse, congenital coronary abnormalities, spasm, trauma, systemic vasculitis, or hematologic disease. AMI has occasionally been reported in young people with hyperhomocysteinemia (HHcy). However, there have been no real reports of AMI in young patients with pulmonary tuberculosis (PTB), much less with HHcy and PTB. Here, we present a rare case of acute anteroseptal myocardial infarction in a 27-year-old man with HHcy and PTB, who was treated successfully with a combination of medications and percutaneous coronary intervention (PCI), and analyze the etiology of the patient's disease.

\section{Case Report}

A 27-year-old man initially presented at the end of September, 2014, to the Second Hospital of Shandong University, Jinan, China, with intermittent blunt chest pain for 9 days. He had a midnight and exertional chest pain radiating to the bilateral shoulders as well as the interscapular regions, which relieved spontaneously within 10 minutes. His cardiovascular history [including coronary artery disease (CAD), diabetes, hypertension and cerebrovascular accident (CVA)] was unremarkable (Table 1). He denied having a family history of premature CAD and hyperlipidemia. He had a history of smoking (20 cigarettes daily) for 4 years. On examination his blood pressure was $143 / 78 \mathrm{mmHg}$, heart rate of 74 beats $/ \mathrm{min}$ and his body mass index was $23 \mathrm{~kg} / \mathrm{m}^{2}$. No pathological findings were detected on physical examination. An electrocardiogram (ECG) revealed rS, STsegment elevation in leads $\mathrm{V}_{1}$ and $\mathrm{V}_{2}$ as well as T-wave inversion in lead I (Fig. 1a) while echocardiography was normal. The level of high-sensitivity troponin I was significantly elevated at $0.49 \mathrm{ng} / \mathrm{mL}$ (normal range: $0-0.06 \mathrm{ng} / \mathrm{mL}$ ) whereas the levels of both myoglobin and creatine kinaseMB fraction (CKMB) were normal. The patient's lipid profile and white blood cell count were also within the normal reference ranges. Acute anteroseptal myocardial infarction was suspected. A chest X-ray showed multiple solid nodules in the left upper lobe of lung (Fig. 2a). Thoracic computed tomography (CT) revealed PTB in the left upper lobe due to the presence of nodules of different sizes and a tree-in-bud pattern (Fig. 2b). The patient was therefore transferred to

${ }^{1}$ Key Laboratory of Cardiovascular Remodeling and Function Research, Chinese Ministry of Education and Chinese Ministry of Health, Department of Cardiology, Qilu Hospital of Shandong University, China and ${ }^{2}$ Department of Cardiology, Shandong Provincial Chest Hospital, China Received for publication November 22, 2014; Accepted for publication April 22, 2015

Correspondence to Dr. Jing-Quan Zhong, zjq_dr@163.com 
Table 1. Summary of Main Laboratory Tests and History of Disease in the Patient and His Parents.

\begin{tabular}{|c|c|c|c|c|c|c|c|c|c|c|}
\hline \multirow{3}{*}{ Variable } & \multicolumn{7}{|c|}{ Value at day } & \multirow{3}{*}{ Father } & \multirow{3}{*}{ Mother } & \multirow{3}{*}{ Reference } \\
\hline & \multirow{2}{*}{$\begin{array}{c}\text { Before transfer } \\
2\end{array}$} & \multicolumn{6}{|c|}{ After admission } & & & \\
\hline & & 2 & 3 & 4 & 6 & 30 & 60 & & & \\
\hline Hs-TnI (ng/mL) & $0.49(0-0.06)$ & - & - & - & - & - & - & - & - & - \\
\hline CKMB (ng/mL) & $3.40(0.3-4.0)$ & 1.01 & 0.76 & 0.50 & 0.42 & - & - & - & - & $<5.10$ \\
\hline $\operatorname{TnI}(\mu \mathrm{g} / \mathrm{L})$ & - & 0.15 & 0.06 & 0.04 & $<0.01$ & - & - & - & - & $<0.01$ \\
\hline Hcy $(\mu \mathrm{mol} / \mathrm{L})$ & - & 51.4 & - & - & - & 30.7 & 18.9 & 10.2 & 8.3 & $4.0-15.4$ \\
\hline Folic acid (nmol/L) & - & - & 5.3 & - & - & 6.0 & 24.8 & - & - & $6.8-36.3$ \\
\hline Vitamin $B_{12}(p g / m L)$ & - & - & 140.8 & - & - & 324.1 & 755.9 & - & - & $200-900$ \\
\hline Vitamin $B_{6}(\mu \mathrm{mol} / \mathrm{L})$ & - & - & 45.3 & - & - & - & - & - & - & $14.6-72.9$ \\
\hline $\mathrm{TG}(\mathrm{mmol} / \mathrm{L})$ & $0.99(0.5-1.8)$ & - & - & 1.22 & - & - & - & 1.09 & 0.63 & $0-1.70$ \\
\hline $\mathrm{TC}(\mathrm{mmol} / \mathrm{L})$ & $4.50(3.23-6.47)$ & - & - & 4.28 & - & - & - & 5.53 & 3.83 & $0-5.20$ \\
\hline $\mathrm{HDL}(\mathrm{mmol} / \mathrm{L})$ & $0.94(0.90-1.68)$ & - & - & 1.01 & - & - & - & 1.10 & 1.22 & $>1.04$ \\
\hline $\mathrm{LDL}(\mathrm{mmol} / \mathrm{L})$ & $2.98(0-3.37)$ & - & - & 2.56 & - & - & - & 2.17 & 1.95 & $<3.12$ \\
\hline $\mathrm{ESR}(\mathrm{mm} / \mathrm{h})$ & - & 6 & - & - & - & - & - & 8 & 11 & $0-15$ \\
\hline $\mathrm{CRP}(\mathrm{mg} / \mathrm{L})$ & - & $<3.44$ & - & - & $<3.44$ & - & - & $<3.44$ & $<3.44$ & $0-8.00$ \\
\hline ASO (IU/mL) & - & 211.0 & - & - & 184.0 & - & - & 162.0 & 147.0 & $0-200.0$ \\
\hline $\mathrm{RF}(\mathrm{IU} / \mathrm{mL})$ & - & $<10.1$ & - & - & $<10.1$ & - & - & $<10.1$ & $<10.1$ & $0-15.00$ \\
\hline CTD-related antibodies & - & Negative & - & - & - & - & - & - & - & \\
\hline \multicolumn{11}{|l|}{ Previous history } \\
\hline Obesity & \multicolumn{7}{|c|}{ No } & No & No & \\
\hline CAD & \multicolumn{7}{|c|}{ No } & No & No & \\
\hline CVA & \multicolumn{7}{|c|}{ No } & No & No & \\
\hline DM & \multicolumn{7}{|c|}{ No } & No & No & \\
\hline CTD & \multicolumn{7}{|c|}{ No } & No & No & \\
\hline Hypertension & \multicolumn{7}{|c|}{ No } & No & No & \\
\hline
\end{tabular}

NOTE: Hs-TnI: high-sensitivity troponin I, CKMB: creatine kinase-MB fraction, TnI: troponin I, Hcy: homosysteine, TG: triglyceride, TC: total cholesterol, HDL: high-density lipoprotein, LDL: low-density lipoprotein, ESR: erythrocyte sedimentation rate, CRP: C-reactive protein, ASO: anti-streptolysin O, RF: rheumatoid factor, CAD: coronary artery disease, CVA: cerebrovascular accident, DM: diabetes mellitus, CTD: connective tissue disease

our hospital for further treatment two days later.

Despite the absence of fever, night sweat, weakness, cough, sputum, and hemoptysis, he was diagnosed with PTB by a pulmonologist according to the chest X-ray and CT findings, a strongly positive tuberculin skin test, and a history of close contact with a colleague who was subsequently diagnosed with PTB one year previously. The contact with the colleague amounted to a $>1$ month period of unconscious exposure to tuberculosis. The patient was thus administered a combination of isoniazid, rifampin, ethambutol and pyrazinamide.

HHcy was diagnosed in the course of evaluating the patient's myocardial enzyme levels. The serum homosysteine level is one of the routinely tested for this purpose. His homosysteine level was found to be elevated at $51.4 \mu \mathrm{mol} / \mathrm{L}$ (normal range: $4.0-15.4 \mu \mathrm{mol} / \mathrm{L}$ ), whereas the serum concentrations of vitamin $\mathrm{B}_{12}$ and folic acid were found to be decreased at $140.8 \mathrm{pg} / \mathrm{mL}$ (normal range: $200-900 \mathrm{pg} / \mathrm{mL}$ ) and $5.3 \mathrm{nmol} / \mathrm{L}$ (normal range: 6.8-36.3 $\mathrm{nmol} / \mathrm{L}$ ), respectively. The patient's serum level of vitamin $\mathrm{B}_{6}$ was $45.3 \mu \mathrm{mol} / \mathrm{L}$, which is within the normal range (14.6-72.9 $\mu \mathrm{mol} / \mathrm{L})$. Hence, he received vitamin supplementation with vitamin $\mathrm{B}_{12}(25 \mu \mathrm{g}$, three times daily) and folic acid (5 mg, three daily).

A variety of immunological tests excluded hypothyroidism and connective tissue disease (CTD) and, importantly, systemic vasculitis (Table 1). His blood pressure on admis- sion was $105 / 77 \mathrm{mmHg}$. His serum troponin I level was elevated at $0.15 \mu \mathrm{g} / \mathrm{L}$ (normal range: $<0.01 \mu \mathrm{g} / \mathrm{L}$ ). ECG showed rS, elevated ST segment and inverted T-waves in the leads $\mathrm{V}_{1}-\mathrm{V}_{3}$ as well as a flattened T-wave in lead I (Fig. 1b). The patient received a standard treatment regimen in accordance with the ST-segment elevation myocardial infarction (STEMI) protocol on the basis of smoking cessation. On the third day after admission, coronary angiography revealed 99\% stenosis in the proximal segment and $80 \%$ stenosis in the mid-segment of the left anterior descending (LAD) artery with thrombolysis in myocardial infarction grade 2 (TIMI 2) flow (Fig. 3a). Furthermore, 80\% stenosis was observed in the proximal segment of the second diagonal $\left(\mathrm{D}_{2}\right)$ artery. The left circumflex (LCx) and right coronary arteries were normal. At the beginning of October, PCI was performed and three sirolimus-eluting stents were implanted (Fig. 3b).

During the 1-month hospitalization period, the man recovered quickly and his chest pain never recurred. His systolic blood pressure during the hospitalization period ranged from 110 to $130 \mathrm{mmHg}$ and his diastolic blood pressure ranged from 60 to $80 \mathrm{mmHg}$. At discharge at the end of October, 2014, ECG was normal (Fig. 1c), and thoracic CT revealed multiple nodules of different sizes and patchy shadows of high density with cavities in the apicoposterior segment of the left upper lobe of the lung, suggesting a significant improvement over the admission (Fig. 2c). The serum concen- 


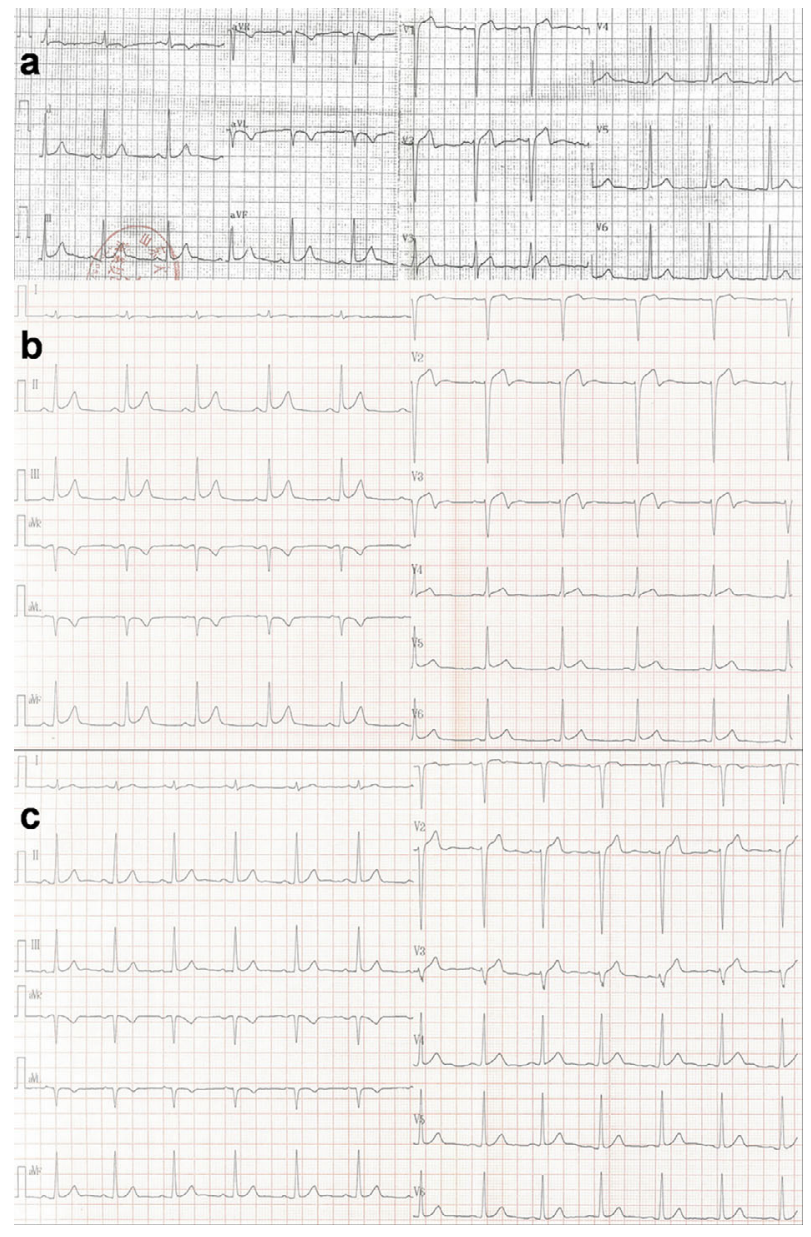

Figure 1. Serial electrocardiograms (ECGs). (a) ECG showing rS, ST-segment elevation in leads $\mathrm{V}_{1}$ and $\mathrm{V}_{2}$, and $\mathrm{T}$-wave inversion in lead I on the third day before admission. (b) ECG showing rS, elevated ST segment, and inverted $\mathrm{T}$ wave in leads $\mathrm{V}_{1}-\mathrm{V}_{3}$ as well as a flattened $\mathrm{T}$-wave in lead $\mathrm{I}$ at admission. (c) $\mathrm{A}$ normal ECG at the end of October, 2014.

trations of homocysteine and folic acid were reduced to 30.7 $\mu \mathrm{mol} / \mathrm{L}$ and $6.0 \mathrm{nmol} / \mathrm{L}$, respectively, whereas his vitamin $\mathrm{B}_{12}$ level had normalized to $324.1 \mathrm{pg} / \mathrm{mL}$. At a 1-month follow-up examination, the patient's homocysteine level was found to be reduced to $18.9 \mu \mathrm{mol} / \mathrm{L}$, whereas serum concentrations of folic acid and vitamin $\mathrm{B}_{12}$ returned to normal (Table 1). In an attempt to rule out the possibility of familial hypercholesterolemia, his parents subsequently underwent a full workup and a series of laboratory tests, including lipid profile, homocysteine, ECG, chest X-ray, and echocardiography, suggesting that they were free of disease (Table 1). Furthermore, his parents also denied having a history of obesity, CAD, diabetes, CVA, CTD and hypertension (Table 1).

\section{Discussion}

AMI in patients below the age of 40 constitutes about $10 \%$ of all cases (1). Furthermore, the incidence of AMI increases with age in all age subgroups from 35 to 54 years of age (2). Conventional risk factors for CAD include advanced age, smoking, hypertension, hyperlipidemia, diabetes, and obesity. The young patient in our case had the classical risk factor of smoking and the two rare risk factors of HHcy and PTB. The reason why he suffered from STEMI may be attributed to two of the three risk factors, or the combination of all three.

Smoking is the single most important risk factor for CAD. Compared with nonsmokers, individuals who consume 20 or more cigarettes per day have a two- to threefold increase in the risk for total CAD (3). Additionally, in young female smokers who consume $\geq 20$ cigarettes per day, the risk for myocardial infarction is increased 14.5-fold (4). Smoking is also the most important modifiable risk factor in young patients (5). Similarly, Larsen et al. (6) demonstrated that smoking remained a powerful contributing risk factor for new-onset STEMI in young patients. However, the high ratio of smoking as a single cardiovascular risk factor for AMI at early ages possibly comes from the spasms induced by smoking rather than from atherosclerotic stenosis (7). Actually, studies on the relationship between smoking and coronary artery lesions in patients aged $<30$ years with AMI were found to be lacking. In our case, the 27-year-old man smoked 20 cigarettes daily for only 4 years. Whether the single risk factor smoking was responsible for the lesions of the $\mathrm{LAD}$ and $\mathrm{D}_{2}$ remains unclear, however, in combination with the other uncommon factors (HHcy and PTB) it may have facilitated the development of atherosclerosis and ultimately caused the onset of STEMI.

Homocysteine is an amino acid involved in the metabolism of methionine, in which folate and vitamins $\mathrm{B}_{12}, \mathrm{~B}_{6}$, and $\mathrm{B}_{2}$ play a key role (8). Normal total plasma homocysteine concentrations range from $5-15 \mu \mathrm{mol} / \mathrm{L}$ in the fasting state (9). HHcy levels are classified as moderate (15-30 $\mu \mathrm{mol} / \mathrm{L})$, intermediate $(>30-100 \mu \mathrm{mol} / \mathrm{L})$, and severe $(>100$ $\mu \mathrm{mol} / \mathrm{L})$ on the basis of concentrations measured during fasting. There is abundant epidemiologic evidence showing that the presence of mild HHcy is an independent risk factor for atherosclerosis in the coronary artery (10). Case-control and prospective studies in Norway have demonstrated that the plasma total homocysteine level is a strong, graded, and independent risk factor for CAD and stroke $(11,12)$. Similarly, in Japan, plasma homocysteine seems to be an independent risk factor for atherosclerotic cardiovascular disease (13). Additionally, a nested case-control study as part of the Japan Collaborative Cohort (JACC) Study confirmed that high serum homocysteine levels were associated with increased mortality from ischemic stroke, CAD and total cardiovascular disease among Japanese individuals (14). In China, the prevalence of HHcy is high, reaching 27.5\%, which is similar to the incidence reported in Brazil and Lebanon, but higher than the incidence reported in Switzerland, Costa Rica, and Korea, and lower than the incidence reported in Iran, Algeria, and coastal West Africa (15). Geographically, the prevalence was high in northern areas, intermediate in central areas, and low in southern areas, and was higher inland than in coastal areas (15). Within each region, 

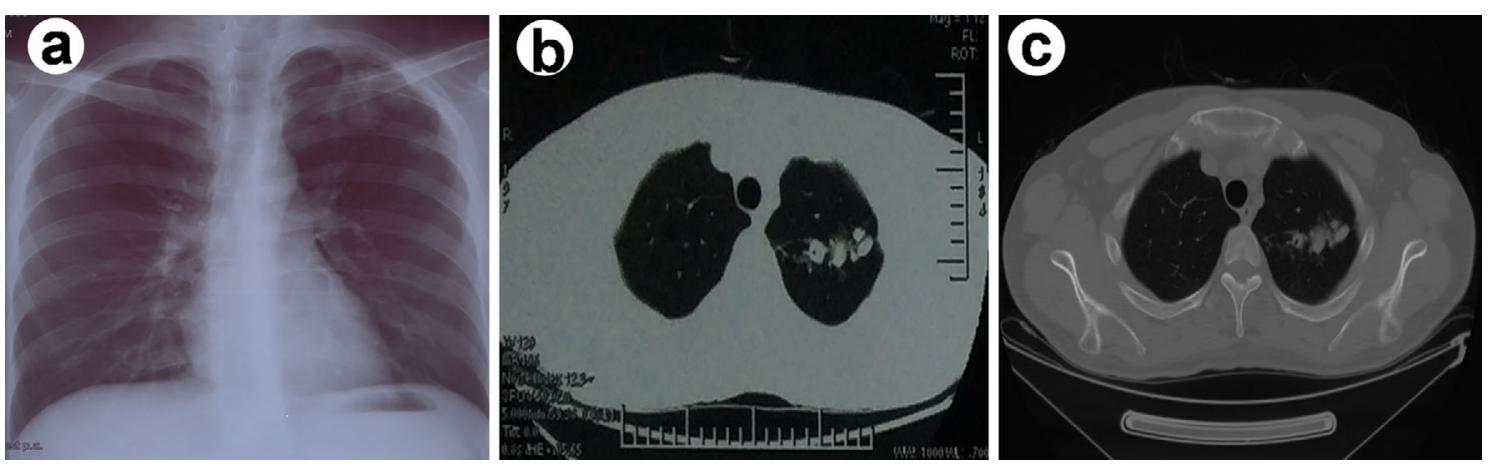

Figure 2. Imaging changes of pulmonary tuberculosis. (a) Chest X-ray revealing multiple solid nodules in the left upper lobe of lung. (b) Thoracic computed tomography (CT) showing pulmonary tuberculosis in the left upper lobe due to different sizes of nodules and a tree-in-bud pattern before the anti-tuberculosis therapy. (c) Thoracic CT revealing multiple nodules of different sizes and patchy shadows of high density with cavities in the apicoposterior segment of left upper lobe of lung, suggesting a significant improvement from admission following anti-tuberculosis therapy.
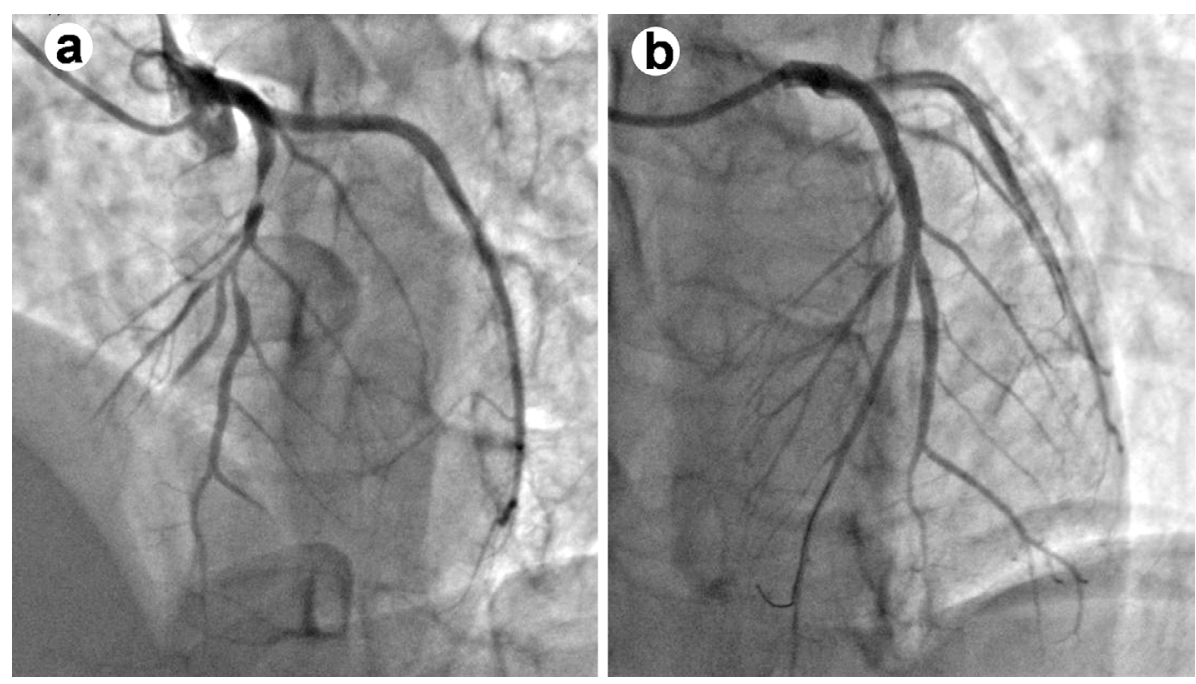

Figure 3. Coronary angiography showing $99 \%$ and $80 \%$ stenosis in the proximal and mid segments of the left anterior descending (LAD) artery with thrombolysis in myocardial infarction grade 2 (TIMI 2) flow, respectively, as well as $\mathbf{8 0 \%}$ stenosis in the proximal segment of the second diagonal artery (a), and three sirolimus-eluting stents implanted in the three segments (b).

men had higher plasma homocysteine concentrations than women. Furthermore, individuals living in urban areas had a $30 \%$ (95\% CI, 1.0-1.6) greater likelihood of having high homocysteine levels than those living in rural areas (16). HHcy was not only highly prevalent but also positively associated with the presence of ischemic stroke in Chinese hypertensive patients $(17,18)$. Additionally, a high homocysteine level was an independent and important risk factor of CAD (19), as well as an independent predictor of 30-day cardiovascular events in patients with AMI (20), and was significantly related to cardiovascular events and all-cause death (21). In our case, the man resided in an urban area was a northerner, thereby matching two of the aforementioned features, however, he was younger than the patients in the above Chinese studies. On the other hand, it has been found that each $5 \mu \mathrm{mol} / \mathrm{L}$ increase in homocysteine level increases the risk of $\mathrm{CAD}$ by $20 \%$, independently of tradi- tional risk factors (22). The mean value of $51.4 \mu \mathrm{mol} / \mathrm{L}$ in our patient was approximately 3.5 -fold above the value of the upper limits of the normal range. Therefore, although he was a smoker with PTB, this single, important risk factor may fully explain the reason why he experienced STEMI at the age of 27 .

Several cases of STEMI with HHcy have been reported since 1997 (23-27). The patients (4 males and 2 females) ranged in age from 25 to 36 with homocysteine levels of 31.47-187 $\mu \mathrm{mol} / \mathrm{L}$. Two of the 6 patients were smokers, 1 had hypertension, 2 had hyperlipidemia, 1 had reduced folate levels, and 3 had decreased vitamin $\mathrm{B}_{12}$ concentrations. The LADs were the culprit arteries in most of the cases apart from the involvement of the LCx in one patient. The reports came to the similar conclusion that the homocysteine level predicted the coronary lesion distribution in the left main artery and the proximal or mid-LAD (28). Four of the 
Table 2. Reported Cases of Acute Myocardial Infarction and Hyperhomocysterinemia or/and Pulmonary Tuberculosis.

\begin{tabular}{|c|c|c|c|c|c|c|}
\hline Reference & 23 & 24 & 25 & 26 & 27 & Current Case \\
\hline Year & 1997 & 2009 & 2012 & 2013 & 2014 & 2014 \\
\hline Age & 35 & 27 & 36 & 25 & 27 & 27 \\
\hline Gender & M & M & M & $\mathrm{F}$ & M & $\mathrm{M}$ \\
\hline \multirow{4}{*}{ Diagnosis } & STEMI & STEMI & STEMI & STEMI & STEMI & STEMI \\
\hline & Hhcy & Hhcy & Hhcy & Hhcy & Hhcy & Hhcy \\
\hline & Hyperlipidemia & $\mathrm{PE}$ & Hypertension & Hyperlipidemia & & TB \\
\hline & & PA & Asthma & & & \\
\hline Culprit Artery & $\mathrm{LCx}$ & LAD & LAD & LAD & LAD & LAD \\
\hline Smoking & No & No & No & Yes & No & Yes \\
\hline \multicolumn{7}{|l|}{ Serum Level } \\
\hline Hcy & $46.4 \mu \mathrm{mol} / \mathrm{L} \uparrow$ & $105 \mu \mathrm{mol} / \mathrm{L} \uparrow$ & $187 \mu \mathrm{mol} / \mathrm{L} \uparrow$ & $31.47 \mu \mathrm{mol} / \mathrm{L} \uparrow$ & $45.2 \mu \mathrm{mol} / \mathrm{L} \uparrow$ & $51.4 \mu \mathrm{mol} / \mathrm{L} \uparrow$ \\
\hline Folate & NA & $12.1 \mathrm{ng} / \mathrm{mL}$ & NA & NA & NA & $5.3 \mathrm{nmol} / \mathrm{L} \downarrow$ \\
\hline Vitamin $B_{12}$ & NA & $158 \mathrm{pg} / \mathrm{mL} \downarrow$ & NA & $50 \mathrm{pg} / \mathrm{mL} \downarrow$ & NA & $140.8 \mathrm{pg} / \mathrm{mL} \downarrow$ \\
\hline Vitamin $\mathrm{B}_{6}$ & NA & NA & NA & NA & NA & $45.3 \mu \mathrm{mol} / \mathrm{L}$ \\
\hline Therapy & NA & Medications & Medications & PCI & Medications & Medications \\
\hline & & PCI & PCI & & & PCI \\
\hline
\end{tabular}

NOTE: STEMI: ST-elevation myocardial infarction, Hhcy: hyperhomocysterinemia, PTB: pulmonary tuberculosis, PE: pulmonary embolism, PA: pernicious anemia, LCx: left circumflex coronary artery, LAD: left anterior descending coronary artery, NA: not available, Hcy: homocysteine, PCI: percutaneous coronary intervention

patients received medications including the dietary supplementation of folate and vitamin $\mathrm{B}_{12}$ and underwent PCI (Table 2).

The nutritional deficiencies in the vitamin cofactors required for homocysteine metabolism (folate, vitamin $\mathrm{B}_{12}$, and vitamin $\mathrm{B}_{6}$ ) may promote HHcy. A number of other factors can increase plasma homocysteine concentrations, including: chronic renal failure, hypothyroidism, pernicious anemia, carcinoma, and some drugs and toxins. Importantly, genetic defects such as cystathionine beta-synthase deficiency and a homozygous deficiency of $N^{5}, N^{10}$ methylenetetrahydrofolate reductase may lead to severe HHcy (29). Additionally, cigarette smoking can raise the plasma homocysteine level $(30,31)$. Smokers with high plasma homocysteine are at greatly increased risk of cardiovascular disease (30). Hence, the lack of folate and vitamin $\mathrm{B}_{12}$ in the 27-year-old smoker may have resulted in the moderately elevated level of homocysteine. However, why did the patient show such low folate and vitamin $B_{12}$ levels? One possibility is due to his smoking and low seafood consumption (seafood is rich in betaine and vitamin $\mathrm{B}_{12}$ ), although he had regularly consumed fresh green-leaf vegetables, fruit, meat and eggs without alcohol intake or any other unusual eating habits.

Several biological mechanisms have been proposed to explain cardiovascular pathological changes associated with HHcy. These include increasing adhesion between neutrophils and endothelial cells, which impair endothelial function, accelerate the cellular uptake of modified low-density lipoprotein, thus stimulating vascular smooth muscle cell proliferation, and promoting thrombosis (32).

Therefore, it would seem necessary to normalize the homocysteine level. However, with regard to clinical trials of homocysteine reduction, several major studies on supplement with folate, vitamin $\mathrm{B}_{6}$, and vitamin $\mathrm{B}_{12}$ have shown no substantive benefits (33-35). As a group, these sharply nega- tive trial results conflict with the supposition made from studies of mendelian randomization that had previously argued for a clear causal relationship between homocysteine concentration and vascular events (36). Despite a lack of evidence that homocysteine reduction lowers risk, there remain specific patient populations for whom homocysteine evaluation may prove appropriate, including individuals who lack traditional risk factors, patients with renal failure, or patients with markedly premature atherosclerosis (37). Therefore, folate and vitamin $\mathrm{B}_{12}$ supplementation, combined with smoking cessation and moderate seafood consumption were performed to reduce the serum homocysteine level in the present patient. Actually, the re-detection of homocysteine, folate and vitamin $B_{12}$ levels demonstrated that the supplementation was effective.

Previous studies have demonstrated that antibodies of mycobacterial heat shock protein are associated with elevated levels of coronary calcification and early atherosclerosis, which may lead to an increased risk of cardiovascular diseases through an autoimmune process $(38,39)$. A recent nationwide population-based cohort study has provided compelling evidence that tuberculosis patients are at higher risk of developing acute coronary syndrome (ACS), and that the risk increases with age (40). In addition, Bakalli et al. (41) showed a rare case of AMI in a 30-year-old female patient with PTB. Kinare et al. (42) reported a severe case of a 19year-old male who died due to a large ventricular aneurysm obtained from myocardial infarction caused by tuberculous coronaritis of the LAD branch. Rodríguez et al. (43) also presented the case of an apparently healthy 21 year-old male who suffered sudden death related to tuberculous coronary arteritis. Together, these findings revealed the possible involvement of an infectious microorganism (Mycobacterium tuberculosis) as the etiologic cause of coronary atherosclerosis resulting in ACS. However, the case reported by Bakalli et al. should be diagnosed as myopericarditis rather than 
AMI. There are several reasons: 1) diffuse ST segments were elevated in all leads except AVR and $V_{1}$, the PR segment was depressed in leads II and $\mathrm{V}_{2}$, and the T-waves inverted before ST-segment normalization; 2) the indications for thromblytic recanalization were not explicit; 3) the diagnosis of AMI was not verified by coronary angiography; and 4) patients with PTB seldom suffer from AMI but frequently suffer from myopericarditis. Therefore, the current case has been the first report of AMI in a young man with PTB to date. Nevertheless, the degree to which PTB was involved the patient's development of STEMI remains unknown.

In conclusion, we presented, for the first time, a rare case of acute anteroseptal myocardial infarction in a 27 -year-old man with HHcy and PTB, who was treated successfully with a combination of medications and PCI. Given that patients under 30 years of age with AMI lack the traditional risk factors, we suggest that homocysteine, folate and B vitamin levels should be regularly evaluated, and that chest Xray or thoracic CT should be routinely ordered to exclude PTB. Aside from routine therapy and PCI, smoking cessation, the supplementation of folate, vitamin $B_{12}$ and vitamin $\mathrm{B}_{6}$, as well as anti-tuberculosis treatment should be performed simultaneously when appropriate.

\section{The authors state that they have no Conflict of Interest (COI).}

\section{Financial Support}

This study was sponsored by the Natural Science Foundation of China (81270238), the Scientific Research Foundation for the Doctoral Degree, State Education Ministry of China (20100131110059) and was supported by the Scientific Development Plan of Shandong Province of China (2012G0021850).

\section{References}

1. Tuzcu EM, Kapadia SR, Tutar E, et al. High prevalence of coronary atherosclerosis in asymptomatic teenagers and young adults: evidence from intravascular ultrasound. Circulation 103: 27052710, 2001.

2. Gupta A, Wang Y, Spertus JA, et al. Trends in acute myocardial infarction in young patients and differences by sex and race, 2001 to 2010. J Am Coll Cardiol 64: 337-345, 2014.

3. Ridker PM, Libby P, Buring JE. Risk markers for atherothrombotic disease. In: Braunwald's Heart Disease: A Textbook of Cardiovascular Medicine. Bonow RO, Mann DL, Zipes DP, Libby PEB, Eds. Elsevier Saunders, Philadelphia, 2012: 914.

4. Dunn NR, Faragher B, Thorogood M, et al. Risk of myocardial infarction in young female smokers. Heart 82: 581-583, 1999.

5. Barbash GI, White HD, Modan M, et al. Acute myocardial infarction in the young--the role of smoking. The Investigators of the International Tissue Plasminogen Activator/Streptokinase Mortality Trial. Eur Heart J 16: 313-316, 1995.

6. Larsen GK, Seth M, Gurm HS. The ongoing importance of smoking as a powerful risk factor for ST-segment elevation myocardial infarction in young patients. JAMA Intern Med 173: 1261-1262, 2013.

7. Yetkin E, Tekin GO, Yagmur J, Turhan H. Effects of smoking on myocardial infarction at early ages. Int J Cardiol 120: 134-135, 2007.

8. Nygard O, Vollset SE, Refsum H, Brattstrom L, Ueland PM. Total homocysteine and cardiovascular disease. J Intern Med 246: 425-
454, 1999.

9. Ueland PM, Refsum H, Stabler SP, Malinow MR, Andersson A, Allen RH. Total homocysteine in plasma or serum: methods and clinical applications. Clin Chem 39: 1764-1779, 1993.

10. Stampfer MJ, Malinow MR, Willett WC, et al. A prospective study of plasma homocyst(e)ine and risk of myocardial infarction in US physicians. JAMA 268: 877-881, 1992.

11. Arnesen E, Refsum H, Bonaa KH, Ueland PM, Forde $\mathrm{OH}$, Nordrehaug JE. Serum total homocysteine and coronary heart disease. Int J Epidemiol 24: 704-709, 1995.

12. Nygard O, Nordrehaug JE, Refsum H, Ueland PM, Farstad M, Vollset SE. Plasma homocysteine levels and mortality in patients with coronary artery disease. N Engl J Med 337: 230-236, 1997.

13. Kario K. Is homocysteine an independent cardiovascular risk factor also in Japanese?. Intern Med 40: 1168-1169, 2001.

14. Cui R, Moriyama Y, Koike KA, et al. Serum total homocysteine concentrations and risk of mortality from stroke and coronary heart disease in Japanese: The JACC study. Atherosclerosis 198: 412-418, 2008.

15. Yang B, Fan S, Zhi X, et al. Prevalence of hyperhomocysteinemia in china: a systematic review and meta-analysis. Nutrients 7: 7490, 2014.

16. Hao L, Ma J, Zhu J, et al. High prevalence of hyperhomocysteinemia in Chinese adults is associated with low folate, vitamin B-12, and vitamin B-6 status. J Nutr 137: 407-413, 2007.

17. Wang Y, Li X, Qin X, et al. Prevalence of hyperhomocysteinaemia and its major determinants in rural Chinese hypertensive patients aged 45-75 years. Br J Nutr 109: 1284-1293, 2013.

18. Wang CY, Chen ZW, Zhang T, et al. Elevated plasma homocysteine level is associated with ischemic stroke in Chinese hypertensive patients. Eur J Intern Med 25: 538-544, 2014.

19. Ni M, Zhang XH, Jiang SL, Zhang Y. Homocysteinemia as an independent risk factor in the Chinese population at a high risk of coronary artery disease. Am J Cardiol 100: 455-458, 2007.

20. Ma Y, Li L, Geng XB, et al. Correlation between hyperhomocysteinemia and outcomes of patients with acute myocardial infarction. Am J Ther (Epub ahead of print).

21. Sun Y, Chien KL, Hsu HC, Su TC, Chen MF, Lee YT. Use of serum homocysteine to predict stroke, coronary heart disease and death in ethnic Chinese. 12-year prospective cohort study. Circ J 73: 1423-1430, 2009.

22. Lentz SR, Haynes WG. Homocysteine: is it a clinically important cardiovascular risk factor? Cleve Clin J Med 71: 729-734, 2004.

23. Glueck CJ, Fontaine RN, Gupta A, Alasmi M. Myocardial infarction in a 35-year-old man with homocysteinemia, high plasminogen activator inhibitor activity, and resistance to activated protein C. Metabolism 46: 1470-1472, 1997.

24. Melhem A, Desai A, Hofmann MA. Acute myocardial infarction and pulmonary embolism in a young man with pernicious anemiainduced severe hyperhomocysteinemia. Thromb J 7: 5, 2009.

25. Ukachukwu V, Idris S, McIlwee A. Acute myocardial infarction in a young patient with hyperhomocysteinaemia. BMJ Case Rep 2012: 2012.

26. Gokay S, Cicek D, Muderrisoglu H. Hyperhomocysteinemia in a young woman presenting with acute myocardial infarction: Case report. Interv Med Appl Sci 5: 39-42, 2013.

27. Peoples K, Kobe D, Campana C, Simon E. Hyperhomocysteinemia-induced myocardial infarction in a young male using anabolic steroids. Am J Emerg Med 32: 948.e1-948.e2, 2014.

28. Koz C, Celebi H, Yokusoglu M, et al. The relation between coronary lesion distribution and risk factors in young adults. Anadolu Kardiyol Derg 9: 91-95, 2009.

29. Welch GN, Loscalzo J. Homocysteine and atherothrombosis. N Engl J Med 338: 1042-1050, 1998.

30. O'Callaghan P, Meleady R, Fitzgerald T, Graham I, European Cg. 
Smoking and plasma homocysteine. Eur Heart J 23: 1580-1586, 2002.

31. Haj Mouhamed D, Ezzaher A, Neffati F, Douki W, Najjar MF. Effect of cigarette smoking on plasma homocysteine concentrations. Clin Chem Lab Med 49: 479-483, 2011.

32. Guthikonda S, Haynes WG. Homocysteine: role and implications in atherosclerosis. Curr Atheroscler Rep 8: 100-106, 2006.

33. Lange H, Suryapranata H, De Luca G, et al. Folate therapy and in-stent restenosis after coronary stenting. $\mathrm{N}$ Engl J Med 350: 2673-2681, 2004.

34. Bonaa KH, Njolstad I, Ueland PM, et al. Homocysteine lowering and cardiovascular events after acute myocardial infarction. $\mathrm{N}$ Engl J Med 354: 1578-1588, 2006.

35. Lonn E, Yusuf S, Arnold MJ, et al. Homocysteine lowering with folic acid and B vitamins in vascular disease. N Engl J Med 354: 1567-1577, 2006.

36. Casas JP, Bautista LE, Smeeth L, Sharma P, Hingorani AD. Homocysteine and stroke: evidence on a causal link from mendelian randomisation. Lancet 365: 224-232, 2005.

37. Loscalzo J. Homocysteine trials--clear outcomes for complex reasons. N Engl J Med 354: 1629-1632, 2006.
38. Zhu J, Katz RJ, Quyyumi AA, et al. Association of serum antibodies to heat-shock protein 65 with coronary calcification levels: suggestion of pathogen-triggered autoimmunity in early atherosclerosis. Circulation 109: 36-41, 2004.

39. Birnie DH, Holme ER, McKay IC, Hood S, McColl KE, Hillis WS. Association between antibodies to heat shock protein 65 and coronary atherosclerosis. Possible mechanism of action of Helicobacter pylori and other bacterial infections in increasing cardiovascular risk. Eur Heart J 19: 387-394, 1998.

40. Chung WS, Lin CL, Hung CT, et al. Tuberculosis increases the subsequent risk of acute coronary syndrome: a nationwide population-based cohort study. Int J Tuberc Lung Dis 18: 79-83, 2014.

41. Bakalli A, Osmani B, Kamberi L, Pllana E. Acute myocardial infarction and pulmonary tuberculosis in a young female patient: a case report. Cases J 1: 246, 2008.

42. Kinare SG, Bhatia BI. Tuberculous coronary arteritis with aneurysm of the ventricular septum. Chest 60: 613-616, 1971.

43. Rodríguez Y, de Armas Y, Capo V, Wissmann G, Goldani LZ, De Waard JH. Sudden death related to tuberculous coronary arteritis. Int J Cardiol 156: e28-e29, 2012.

(C) 2016 The Japanese Society of Internal Medicine http://www.naika.or.jp/imonline/index.html 